\title{
Rift Valley fever ocular manifestations: observations during the 1977 epidemic in Egypt
}

\author{
A. L. SIAM, ${ }^{1}$ J. M. MEEGAN, ${ }^{2}$ AND K. F. GHARBAWI ${ }^{3}$ \\ From the ${ }^{1}$ Faculty of Medicine, Ain Shams University, Cairo, Egypt, ${ }^{2}$ US Naval Medical \\ Research Unit Number 3, American Embassy, Cairo, Egypt, and ${ }^{3}$ Ministry of Public Health, \\ Cairo, Egypt
}

SUMMARY Ocular manifestations resulting from Rift Valley fever (RVF) virus infection were studied during an extensive RVF epidemic in Egypt during 1977. Colour photography and fluorescein angiography of 7 serologically diagnosed patients showed the commonest manifestations to be macular, paramacular, and/or extramacular retinal lesions, often occurring bilaterally. Haemorrhage and oedema were frequently associated with the lesions, and vasculitis, retinitis, and vascular occlusion were also observed. Patients were monitored during a 6-month convalescence, and, though resorption of the lesions occurred, approximately half the patients experienced permanent loss of visual acuity. Ocular disease was one form of the clinical spectrum of RVF; acute febrile, encephalitic, and fatal haemorrhagic RVF illnesses were also observed during the epidemic.

Rift Valley fever (RVF) is an arthropod-borne viral disease primarily affecting domestic animals with occasional involvement of man. ${ }^{1}$ Before 1975 RVF in man was described as a mild, dengue-like, febrile illness. ${ }^{2-4}$ However, a report by Van Velden et al $^{5}$ described 4 human RVF fatalities and 1 case of retinitis during an RVF epizootic in South Africa in 1975. A number of earlier studies had reported ocular complications in suspected RVF patients. ${ }^{6-8}$ The general syndrome was one of macular and paramacular oedema with exudate-like lesions and haemorrhages. The most extensive report ${ }^{9}$ described 3 putative cases of RVF retinitis and 1 clinically indistinguishable case of tick-bite rickettsial fever retinitis. None of these previous reports included definitive diagnosis by virus isolation or the demonstration of serological conversion in paired acute and convalescent serum samples.

From October to December 1977 an extensive epidemic of an acute febrile illness occurred in the Nile Delta area of the Arab Republic of Egypt. Although the usual disease was an uncomplicated febrile illness, numerous cases of encephalitic, ocular, and fatal haemorrhagic disease were reported. The agent responsible for the febrile, encephalitic, and fatal haemorrhagic illnesses was RVF

Correspondence to Publications Editor, NAMRU-3, FPO, NY 09527, USA. virus. ${ }^{10}$ This report describes retinal lesions in patients infected with RVF during the epidemic.

\section{Patients and methods}

PATIENTS

From October to December 1977 an increased number of patients were referred to our clinic from an area in the Nile Delta $70 \mathrm{~km}$ north-east of Cairo (Sharqiya and Qalyubiya Governorates). They had similar clinical findings characterised by retinalexudate-like lesions and haemorrhages. A study group of 7 patients representing the most frequently encountered lesions are presented in this report.

OPHTHALMOLOGICAL PROCEDURES

Ocular examination of all patients was performed by standard procedures, including an anterior segment examination with a slit-lamp and a fundus examination with the indirect ophthalmoscope. Clinical manifestations were photographed in all but the most severe cases, where a hazy view of the fundus often prevented clear photography. Fluorescein angiography was performed in the acute stage and at varying periods during convalescence.

\section{SEROLOGICAL PROCEDURES}

The methods of Casals ${ }^{11}$ were used to treat serum samples, prepare RVF (Zagazig strain) viral antigen, 
Table 1 Ocular findings in 7 RVF patients representing the variety of lesions observed during the epidemic. Patients were monitored for a period of 6 months

\begin{tabular}{|c|c|c|c|c|}
\hline Case & Initial examination & $V A R$ & $V A L$ & Convalescent examination \\
\hline 1 & $\begin{array}{l}\text { Macular exudate-like lesion with associated } \\
\text { haemorrhage in right eye. Severe uveitis with } \\
\text { KPs and vitreous haze }\end{array}$ & CF $50 \mathrm{~cm}$ & $6 / 60$ & $\begin{array}{l}\text { No improvement of VA; some resorption of } \\
\text { exudate-like lesion }\end{array}$ \\
\hline 2 & Mild macular exudate-like lesion in right eye & $3 / 60$ & $6 / 9$ & $\begin{array}{l}\text { VA of right eye improved to } 6 / 9 \text {; small } \\
\text { paramacular scar remains }\end{array}$ \\
\hline 3 & Paramacular exudate-like lesion in right eye & $2 / 60$ & $6 / 36$ & VA of right eye improved to $6 / 60$ \\
\hline 4 & $\begin{array}{l}\text { Macular and paramacular exudate-like lesions } \\
\text { in right eye and paramacular exudate-like } \\
\text { lesions in left eye }\end{array}$ & $1 / 60$ & $2 / 60$ & $\begin{array}{l}\text { No improvement in VA of right eye; left eye } \\
\text { improved to } 6 / 36 \text {; some resorption of } \\
\text { exudate-like lesions in both eyes }\end{array}$ \\
\hline 5 & $\begin{array}{l}\text { Macular exudate-like lesion with vasculitis and } \\
\text { peripapillary choroidal ischaemia in right eye. } \\
\text { Extramacular exudate-like lesions in left eye }\end{array}$ & $1 / 60$ & $6 / 9$ & VA improved to $6 / 36$ in right eye \\
\hline 6 & $\begin{array}{l}\text { Bilateral macular exudate-like lesions with } \\
\text { associated haemorrhages and severe bilateral } \\
\text { vasculitis }\end{array}$ & $1 / 60$ & CF $50 \mathrm{~cm}$ & $\begin{array}{l}\text { No improvement VA of left eye; right eye } \\
\text { improved to } 6 / 36\end{array}$ \\
\hline 7 & $\begin{array}{l}\text { Bilateral severe exudate-like lesions with } \\
\text { haemorrhage; infarction-like areas in all } \\
\text { quadrants. Severe uveitis with KPs and } \\
\text { vitreous haze }\end{array}$ & No PL & No PL & $\begin{array}{l}\text { No improvement of vision despite resorption } \\
\text { of exudate-like lesions; vessels appear } \\
\text { sheathed and occluded; optic atrophy } \\
\text { occurred }\end{array}$ \\
\hline
\end{tabular}

$\mathrm{VA}=$ visual acuity. $\mathrm{KP}=$ keratic precipitates. $\mathrm{CF}=$ counting fingers. $\mathrm{PL}=$ perception of light.

and measure serum antibodies to RVF virus in the haemagglutination-inhibition (HI) and complement-fixation $(\mathrm{CF})$ tests.

\section{Results}

All patients (Table 1) presented with a history of an acute febrile illness, usually of 3-4 days' duration, characterised by retro-orbital pain, headache, joint pain, and frequently by episodes of recurring fever. Visual symptoms developed 7-20 days after the onset of the initial febrile period.

When patients were seen soon after their febrile phase, acute and convalescent serum samples were obtained. A 4-fold or greater rise in HI or CF antibody titre between these paired samples confirms recent infection, and indicates the clinical illness was aetiologically related to the virus used in the test. ${ }^{12}$ In a preliminary communication we reported 2 cases in which a 4-fold or greater rise in antibody titre to RVF virus established retinitis as resulting from RVF virus infection. ${ }^{13}$ As noted in Table 2, while only these 2 patients had a 4-fold increase in antibody titre during the observation period, all patients had greatly elevated HI and CF antibody titres to RVF virus.

In an area where RVF is endemic, the presence of antibodies to RVF virus in a single blood sample need not represent a response to a recent febrile illness. However, a retrospective serological survey of more than 700 blood samples collected before
1977 from people living in the Nile Delta was negative for antibodies to RVF virus, thus indicating the disease was not endemic in Egypt before the 1977 outbreak. Therefore, our patients from whom only 1 blood sample was obtained were assumed to have had an RVF virus infection just before their visit to our clinic since they: (a) had substantially raised RVF virus $\mathrm{HI}$ and $\mathrm{CF}$ antibody titres; $(b)$ were geographically from the epidemic area; and (c) were seen during the epidemic period. Addi-

Table 2 Haemagglutination-inhibition $(H I)$ and complement-fixation (CF) tests for antibodies to $R V F$ virus

\begin{tabular}{lllll}
\hline \multirow{2}{*}{ Case } & \multicolumn{2}{l}{ HI antibody titre* } & \multicolumn{2}{l}{ CF antibody } \\
\cline { 2 - 5 } & $\begin{array}{l}\text { First } \\
\text { sample }\end{array}$ & $\begin{array}{l}\text { Second } \\
\text { sample** }\end{array}$ & $\begin{array}{l}\text { First } \\
\text { sample }\end{array}$ & $\begin{array}{l}\text { Second } \\
\text { sample** }\end{array}$ \\
\hline 1 & 160 & 1280 & 16 & 64 \\
2 & 640 & - & 64 & - \\
3 & 160 & 640 & 64 & 128 \\
4 & 640 & - & 64 & - \\
5 & 320 & - & 64 & - \\
6 & 640 & 640 & 32 & 32 \\
7 & 5120 & 5120 & 256 & 256 \\
\hline
\end{tabular}

*The titre is expressed as the reciprocal of the maximum serum dilution yielding positive test results. **Obtained 1-2 months after the first sample. 


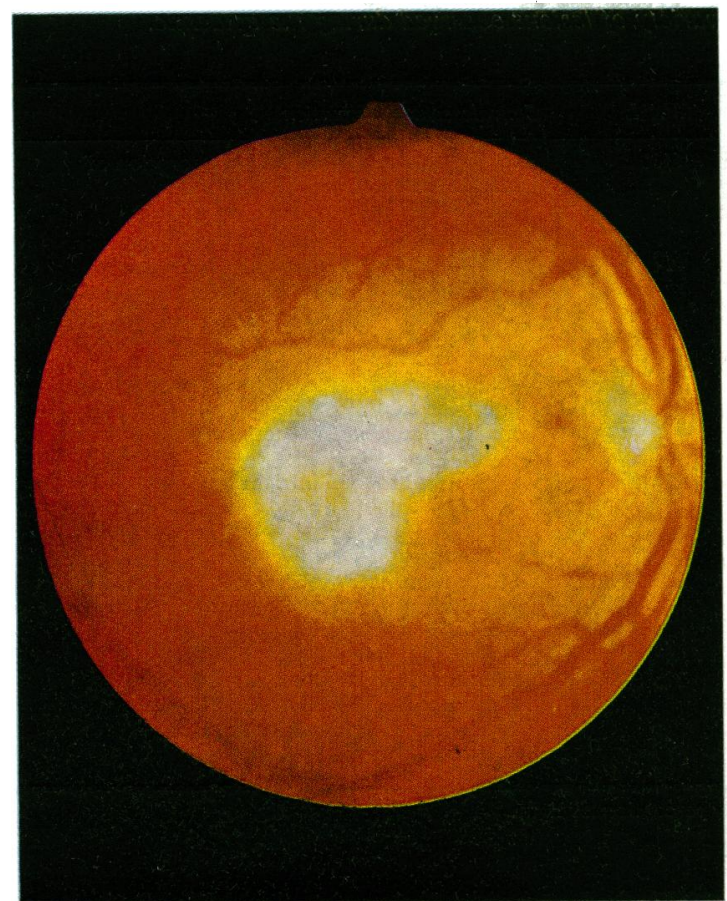

Fig. 1 (a) Photography of case 1 at the time of initial examination reveals an extensive macular lesion with haemorrhage and oedema

tionally this group of patients was tested and found negative for raised levels of CF antibodies to selected rickettsial and viral agents which might cause ocular manifestations including Q-fever, measles, rubella, varicella, herpes simplex $\mathrm{I}$, dengue $\mathrm{I}$, and influenza type A, B, and C (data not shown). Thus we believe the ocular lesions seen in these 7 patients to have resulted from RVF virus infection.

Table 1 summarises the ocular findings in our study group of 7 cases and includes observations during a 6-month convalescent period. Each patient had either macular, paramacular, and/or extramacular exudate-like lesions. Unfortunately no tissues were available for histopathological studies, and it could not be determined if these lesions were truly exudates, or perhaps swollen and opaque cells, or axoplasm. For the purpose of demonstrating the major types of findings with this disease we have presented the 7 patients on the basis of their most illustrative clinical findings.

FINDINGS IN PATIENTS

Macular and paramacular lesions. Case 1 (Fig. 1) was a 50-year-old male whose macular lesion represented the type most frequently encountered (in both severe and milder forms) during the epi-

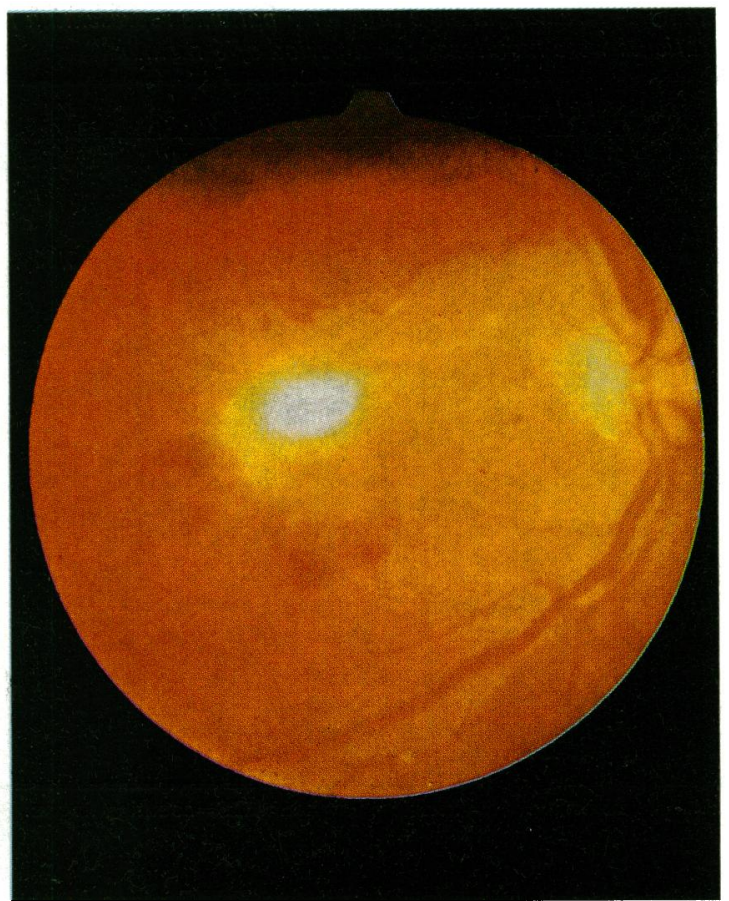

Fig. 1 (b) Examination of case 1 after 6 weeks shows partial resorption of haemorrhage, resolution of oedema, and partial resolution of lesion

demic. The patient was seen 10 days after the onset of fever. Vision was reduced to counting fingers at $0.5 \mathrm{~m}$, and the ocular examination revealed an extensive retinal lesion that could be seen through a vitreous haze. The lesion was roughly triangular, with the apex toward the optic disc, and retinal oedema and haemorrhages were present. The vitreous turbidity increased progressively over the next few weeks, and was associated with aqueous flare and fine keratic precipitates. Subsequent examinations at 3-week intervals showed marked resorption of the lesion (Fig. 1b), and only a macular scar remained 6 months later. No visual improvement occurred throughout the 6 month period.

Case 2 (Fig. 2) was a 26-year-old male who had a retinal lesion of a milder form consisting of oval, paramacular, exudate-like lesions associated with macular oedema, but without retinal haemorrhages. Nearly complete resorption occurred during the next 6 months with only a small paramacular scar remaining (Fig. 2d). Macular oedema completely resolved, and visual acuity improved from 3/60 at the initial examination to $6 / 9$ after 6 months. The media were clear throughout the 6-month period. In the acute phase fluorescein angiography showed choroidal fluorescence to be obscured in the area 


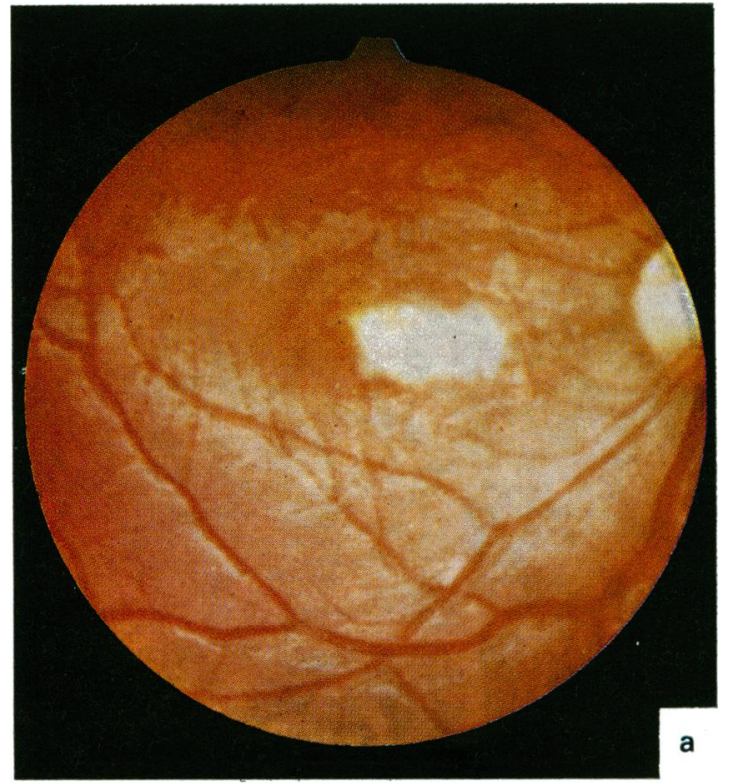

Fig. 2 (a) (b) (c) Photography and fluorescein angiography of case 2 at initial examination reveals oedema and a lesion bordering the macula

corresponding to the lesion. Figure $2 b$ shows evidence of delayed peripapillary choroidal filling in the arteriovenous phase. Fluorescein angiography after 6 months showed a window defect at the paramacular scar and a residual delay in peripapillary choroidal filling (Fig. 2e).

Case 3 (Table 1) was a 51-year-old male with somewhat milder, paramacular, exudate-like lesions which completely resolved within 6 weeks.

Case 4 (Table 1) was a 52-year-old male with bilateral, paramacular, exudate-like lesions. Bilateral lesions were observed in the majority of cases seen during the epidemic.

Vasculitis and vascular occlusion. Evidence of vasculitis in the vicinity of the lesion can be seen in the fluorograms of case 2 (Fig. 2c). Additionally case 5 (Fig. 3) was a 53-year-old male with vasculitis which was not apparent on colour photography but was revealed with fluorescein angiography. Scattered macular, paramacular, and peripapillary exudate-like lesions were observed at initial examination. Some haemorrhages were also evident. The macular area was involved in the right eye (visual acuity $1 / 60$ ), and the left eye had lesions bordering but not directly involving the macula (visual acuity
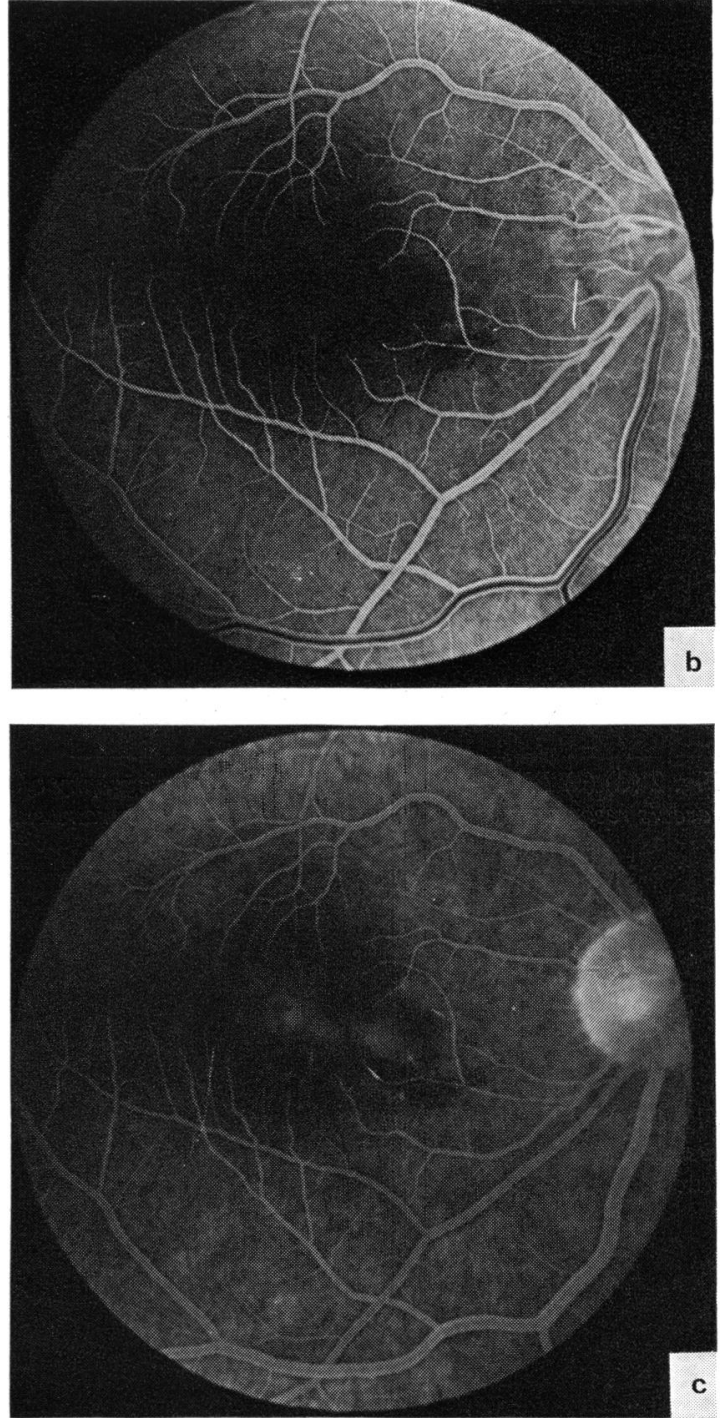

6/9). Fluorescein angiography revealed several minute vessels, particularly in the left eye passing from the disc toward the macula, from which dye leakage appeared to indicate vessel damage (Fig. 3c). Visual acuity improved to $6 / 36$ during 6 months of convalescence.

Case 6 (Fig. 4) was a 52-year-old male who displayed extensive, bilateral, exudate-like lesions and haemorrhages at the posterior pole, with associated sheathing of vessels in an area near the left fundus. Fluorescein angiography showed evidence of widespread vasculitis and vascular occlusion (Figs. 4b and c) associated with extensive leakage in the late phase of the angiograms (Fig. 4d). Examination after 

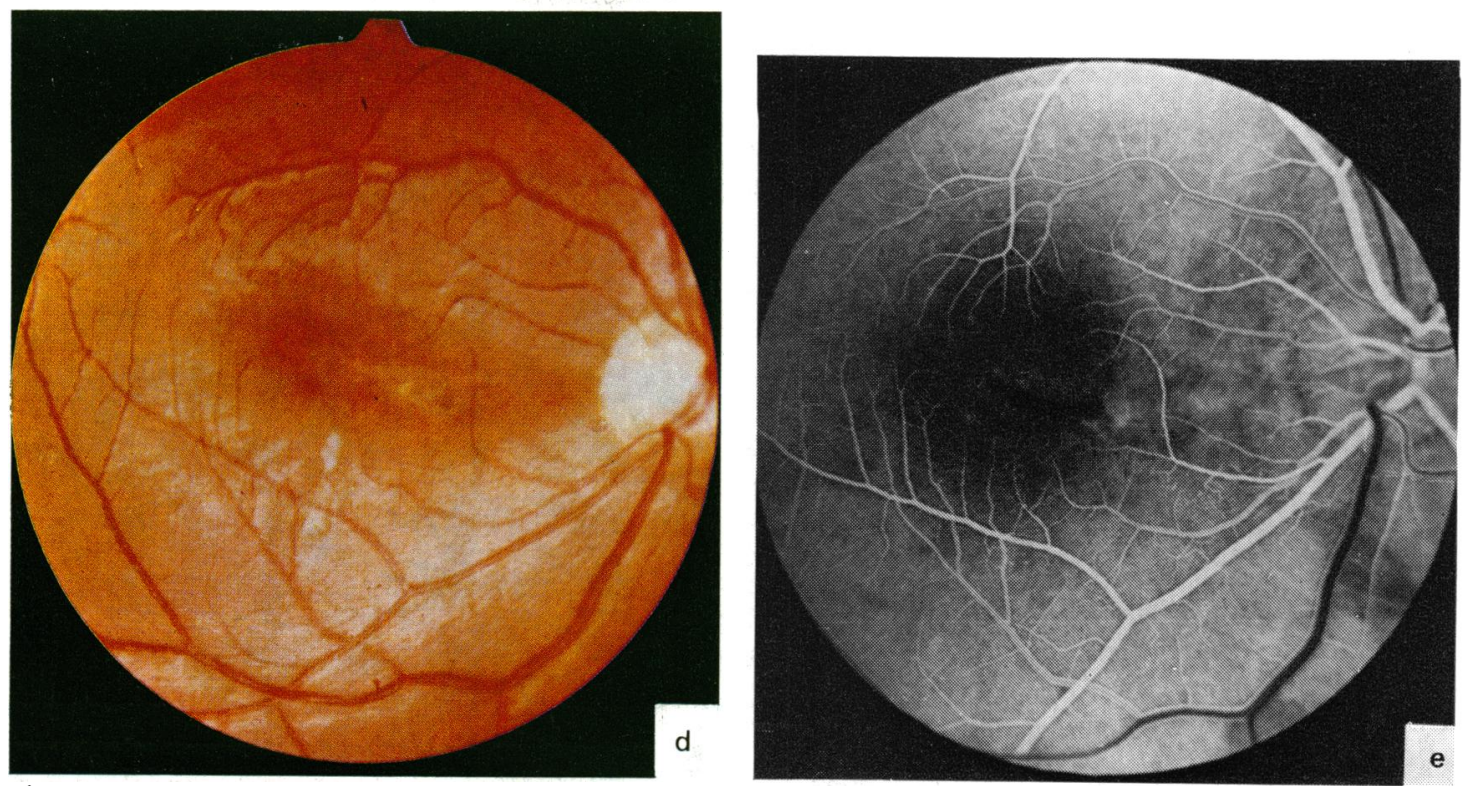

Fig. 2 (d) (e) Photography and fuorescein angiography of case 2 during an examination after a 6-month convalescence reveals resorption of the lesion and a remaining paramacular scar

Fig. 3 (a) Bilateral lesions seen at initial examination of case 5
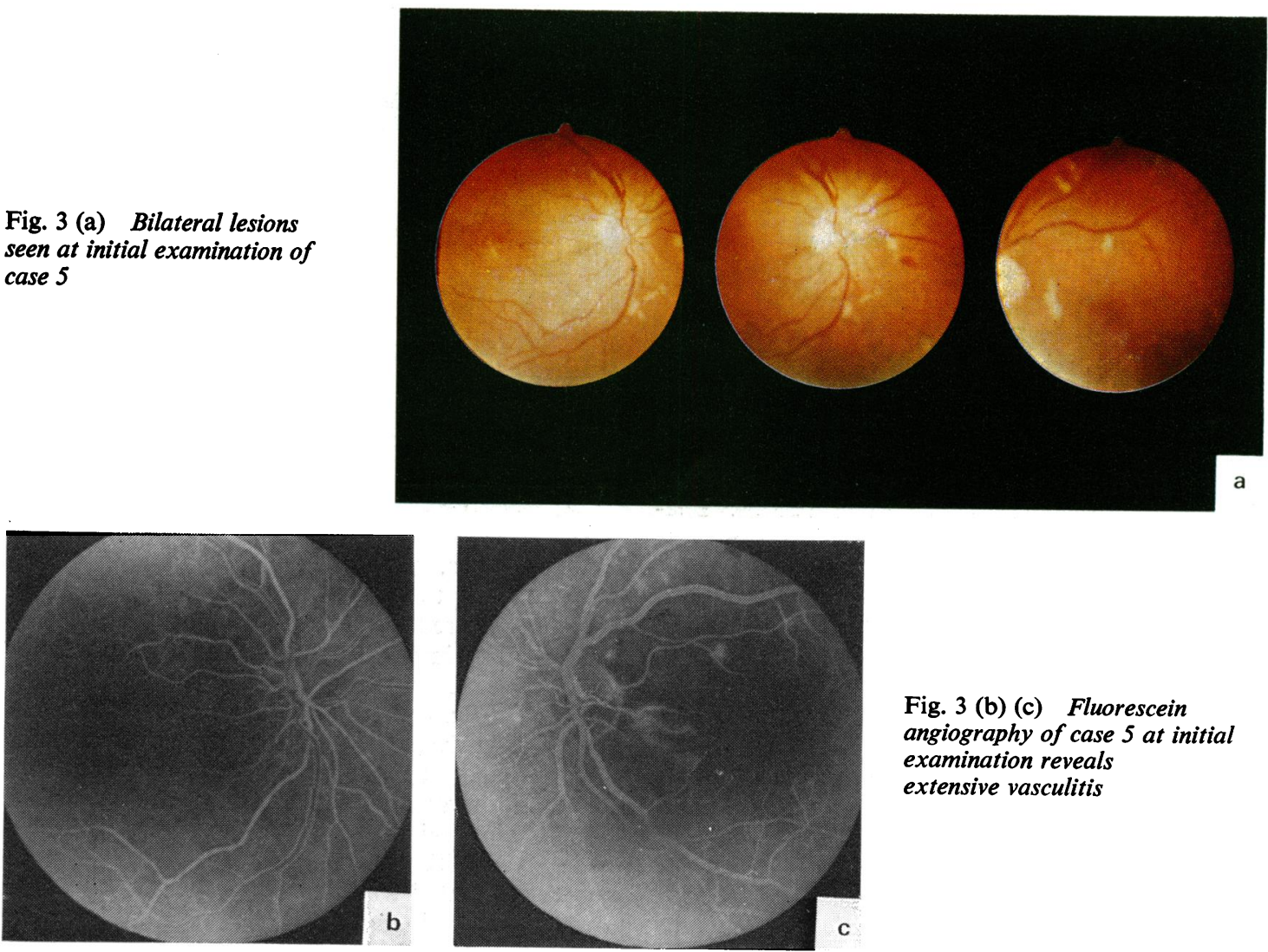

Fig. 3 (b) (c) Fluorescein angiography of case 5 at initial examination reveals extensive vasculitis 
Fig. 4 (a) Photography of case 6 at initial visit

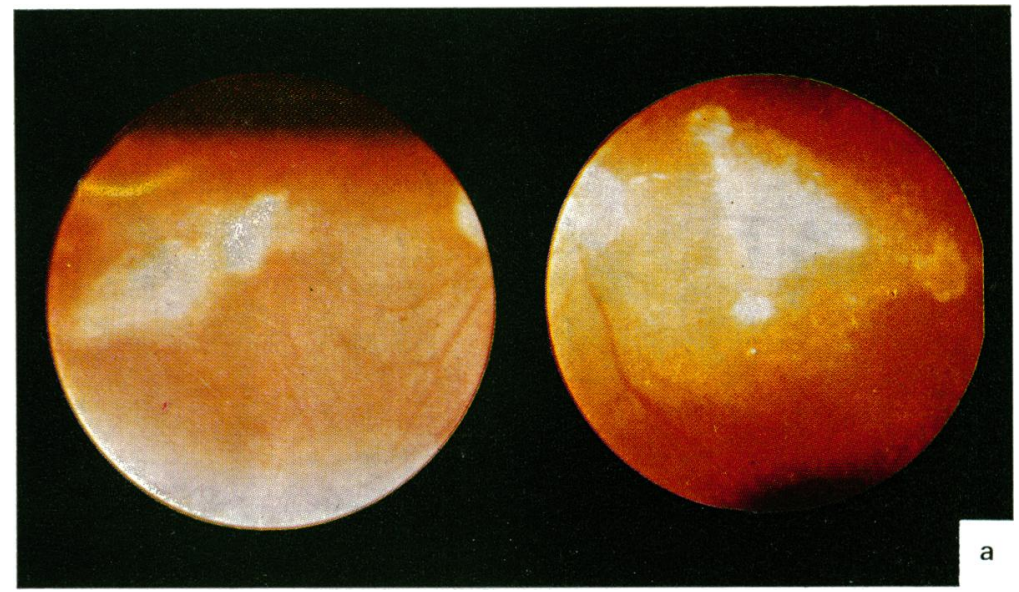

6 months showed improvement of visual acuity to $6 / 36$ in the right eye but no improvement in the left eye. Almost complete resorption of the exudate-like lesions and the haemorrhages occurred during this period. Fluorescein angiography showed residual sheathed vessels with a general absence of macular vessels in the left eye.

Case 7 (Fig. 5) was a 55-year-old diabetic male who lost vision in both eyes after recovery from a 1-week episode of fever. Initial examination revealed extensive macular and paramacular exudate-like lesions with haemorrhages in both fundi. The retinal

Fig. 4 (b) (c) (d) Fluorescein angiography of case 6 during initial examination reveals extensive vasculitis and sheathing of retinal vessels
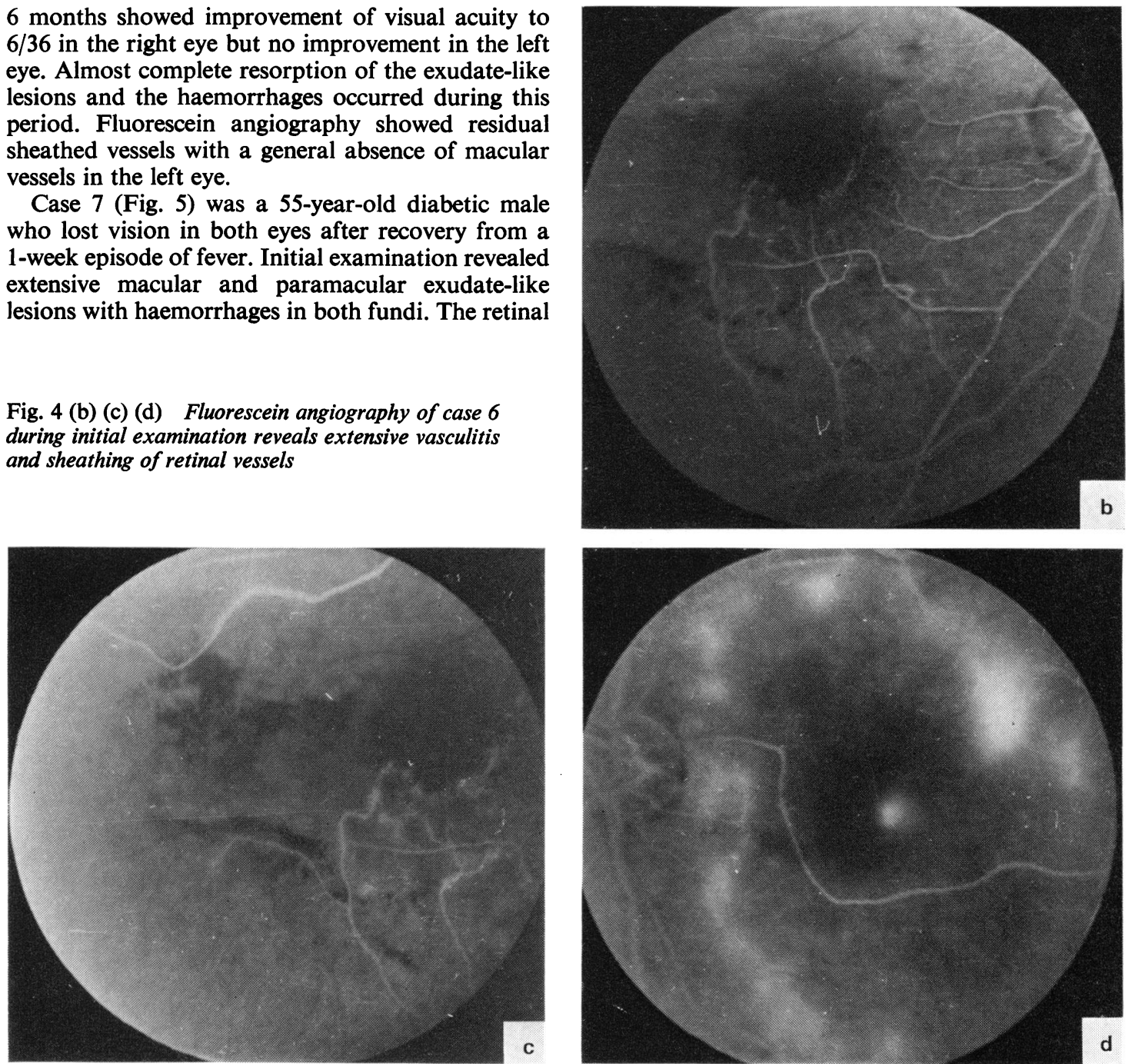

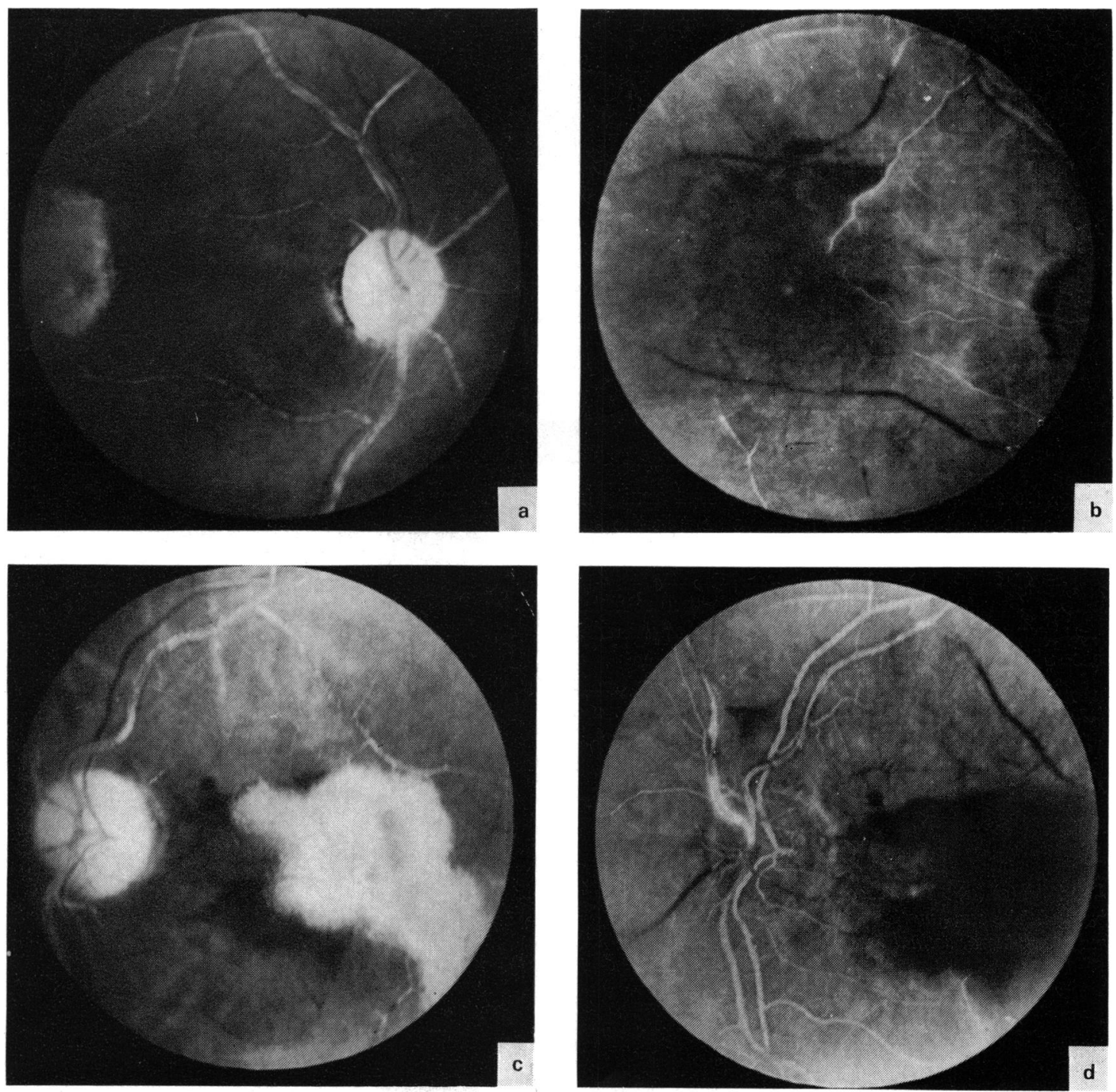

Fig. 5 Fluorescein angiography of case 7 at initial examination. Extensive lesions in both the right (a) (b) and left (c) (d) eyes are associated with vascular abnormalities

vessels of both eyes appeared sheathed. Fluorescein angiograms showed obscuration of the background fluorescence in the area of the lesions. In both eyes the vessels at the optic disc and macula appeared extensively damaged (Fig. 5).

Uveitis. A marked vitreous haze associated with aqueous flare and fine keratic precipitates was present in cases 1 and 7. However, there was no evidence of uveitis in the other 5 patients in the study group, and few cases of uveitis were seen among the larger number of suspected RVF cases encountered during the epidemic. Clearing occurred slowly in these 2 cases, but no synechiae developed.

\section{Discussion}

Previous reports of RVF ocular complications have been limited. Gear et al. ${ }^{8}$ described a blurred vision syndrome in patients suspected of having RVF. Joubert et al ${ }^{14}$ reported on a patient with retinal 
haemorrhages and a second with retinitis and macular exudate-like lesions. Freed $^{7}$ described a well defined, macular, exudate-like lesion in a putative RVF patient. Schrire ${ }^{6}$ reported on 5 suspected RVF cases with unilateral, macular, exudatelike lesions and 1 case with retinal detachment. Cohen and Luntz ${ }^{9}$ described 3 cases of RVF retinitis and 1 case of tick-bite fever rickettsial retinitis. Detailed fluorographic data in the latter report suggested vascular occlusion with primary involvement of the retinal circulation. However, the localised areas of retinal ischaemia and exudate formation were indistinguishable in the RVF and tick-bite fever (Rickettsia conori) disease. Consequently, diagnostic serological data must be cautiously interpreted, especially in an endemic RVF area. Easterday ${ }^{1}$ reviewed the early literature and emphasised that the role of RVF virus in the aetiology of ocular disease was unresolved, since all previous diagnoses were made from 1 serum sample collected well after the onset of ocular lesions.

The present study further establishes that macular exudate-like lesions are indeed a complication of infection with RVF virus. However, unlike previous reports, bilateral lesions were frequently encountered among the patients seen during the epidemic, and in addition to macular lesions paramacular and extramacular lesions were also frequently observed.

The presence of vasculitis as well as retinitis most probably results in the development of the lesions. The severity of the lesions appeared to be related to the size and number of vessels affected. In cases of milder macular and paramacular lesions the minute vessels were involved. In the more severe cases retinitis, extensive vasculitis in larger vessels, and vascular occlusion probably contributed to the lesion. The delayed peripapillary choroidal filling observed in cases 2 (Fig. 2b) and 5 (Fig. 3b) during the arteriovenous phase may indicate choroidal involvement (other cases not included in this study appeared to show this more obviously, both in the peripapillary and macular area).

During the epidemic period we examined approximately 80 patients from the outbreak area with what clinically appeared to be RVF retinitis. Cultural factors prevented collection of serum from each person, and usually only males sought medical assistance. However, a total of 22 patients were examined serologically, and each had raised HI and CF antibody titres to RVF. We are continuing to monitor many of these patients, and approximately $40-50 \%$ have permanent loss of visual acuity following the resorption of lesions.

The retinal complications of RVF presented in this report were one phase of the clinical spectrum of RVF disease observed during the epidemic. Uncomplicated, dengue-like disease was the most prevalent clinical illness. However, fatal haemorrhagic-like disease and an encephalitic illness have also been seen as resulting from RVF virus infection. ${ }^{10}$ Owing to the extent of the epidemic definitive attack rates, incidence of complications, age and sex distribution, and other epidemiological statistics have not yet been determined. However, it has been estimated that morbidity was between 20000 and 200000 and mortality in excess of 600 .

All previous RVF outbreaks have been geographically limited to sub-Saharan Africa ${ }^{1}$ and predominantly affected domestic animals. Human disease was usually recorded during these epizootics, but was always described as an uncomplicated febrile illness. Before the Egyptian outbreak only 4 RVF fatalities had been reported despite the scientific observation of the disease since 1930 . Consequently, the Egyptian outbreak represents the largest and most severe RVF epidemic yet recorded. The isolation of the virus in Egypt also represents the northern-most spread of the disease. The source of the outbreak has not been determined, but the occurrence of a RVF epizootic in the Sudan in $1973^{15}$ raises the likelihood that the virus could have been introduced into Egypt from the south by infected camels or other livestock.

The unusually wide vertebrate and invertebrate host range of RVF virus probably has contributed to its spread. The virus now circulates in a variety of ecological settings in a $7000 \mathrm{~km}$ north-south range across Africa. The possible continued spread of RVF virus within Africa, as well as to other continents is a distinct possibility of which medical personnel should be cognisant.

This study was supported by funds from Ain Shams University and Research Project MR041.09.01-0165, Naval Medical Research and Development Command, National Naval Medical Center, Bethesda, Maryland, USA. The opinions and assertions contained herein are the private ones of the author and are not to be construed as official or as reflecting the views of the Department of the Navy or of the naval service at large.

\section{References}

${ }^{1}$ Easterday BC. Rift Valley fever. Adv Vet Sci 1965; 10: 65-127.

${ }^{2}$ Daubney R, Hudson JR, Garnham PC. Enzootic hepatitis or Rift Valley fever: An undescribed virus disease of sheep, cattle and man from East Africa. J Pathol Bacteriol 1931; 34: 545-79.

${ }^{3}$ Findley GM. Rift Valley fever or enzootic hepatitis. Trans $R$ Soc Trop Med Hyg 1932; 25: 229-65.

${ }^{4}$ Mundel B, Gear J. Rift Valley fever: I. The occurrence of human cases in Johannesburg. A Afr Med J 1951; 25: 797-800. 
${ }^{5}$ Van Velden DJ, Meyer JD, Oliver J, Gear JH, McIntosh B. Rift Valley fever affecting humans in South Africa: a clinicopathological study. S Afr Med J 1977; 51: 867-71. ${ }^{6}$ Schrire L. Macular changes in Rift Valley fever. $S$ Afr Med $J$ 1951; 25: 926-30.

'Freed I. Rift Valley fever in man complicated by retinal changes and loss of vision. $S$ Afr Med J 1951; 25: 930-2. ${ }^{8}$ Gear J, de Meillon B, Measroch V, Harwin R, Davis DH. Rift Valley fever in South Africa. 2. The occurrence of human cases in the Orange Free State, the Northwestern Cape Province, the Western and Southern Transvaal. B. Field and laboratory investigations. $S$ Afr Med J 1951; 25: 908-12.

${ }^{\circ}$ Cohen C, Luntz MH. Rift Valley fever and rickettsial retinitis including fluorescein angiography. Klin Monatsbl Augenheilk 1976; 169: 685-99.

${ }^{10}$ Meegan JM et al. Lancet 1979; in press.
${ }^{11}$ Casals J. Immunological techniques for animal viruses. Methods Virol 1967; 3: 113-98.

${ }^{12}$ Monath TP. Togaviruses, Bunyavirus, and Colorado tick fever virus. In: Rose NR, Friedman $\mathrm{H}$, eds. Manual of Clinical Immunology. Washington, DC: American Society for Microbiology, 1976: 456-62.

${ }^{13}$ Siam AL, Meegan JM. Trans R Soc Trop Med Hyg 1979 (in review).

${ }^{14}$ Joubert JDS, Ferguson AL, Gear J. Rift Valley fever in South Africa. 2. The occurrence of human cases in the Orange Free State, the North-western Cape Province, the Western and Southern Transvaal. A. Epidemiological and clinical findings. $S$ Afr Med J 1951; 25: 890-1.

${ }^{15}$ Eisa M, Obeid HMA, El Sawi ASA. Rift Valley fever in Sudan. Results on field investigations of the first epizootic in Kosti District 1973. Bull Animal Health Prod Africa 1977; 25 : 343-7. 